\title{
ANALIZA PRACY SYSTEMU PODGRZEWANIA PEYTY BOISKA SPORTOWEGO Z WYKORZYSTANIEM POMPY CIEPLA W TRAKCIE JEJ EKSPLOATACJI
}

\begin{abstract}
W artykule przedstawiono system podgrzewania płyty boiska sportowego znajdującego się w Praszce niedaleko centrum przy jednej ze szkół. Opisano jego główne elementy oraz przedstawiono rodzaje gruntowych wymienników ciepła. System podgrzewania murawy w zimie za pomocą pompy ciepła odbiera pokłady energii cieplnej dolnego źródła i przekazuje ją do górnego źródła, które podgrzewa murawę boiska. Podczas dużych, długotrwałych mrozów system nie działa poprawnie. Sterownik pompy ciepła, ze względu na zbyt niskie temperatury solanki na wypływie z pompy, wyłącza ją co dzieję się przy temperaturze $-10{ }^{\circ} \mathrm{C}$. Dodatkowo zbierający się lód na ściankach rur uniemożliwia regulację zaworów przez co pompa ciepła musi być wyłączona do momentu stopienia się lodu. Podczas tych przestojów zanika możliwość podgrzewania murawy; co za tym idzie w zimie podczas opadów śniegu system nie wypełnia swojej podstawowej roli. Ponadto został również przedstawiony system akumulacji ciepła wraz z opisem jego głównych elementów. Ten system ma za zadanie zmagazynowanie jak największej ilości ciepła w gruncie podczas ciepłych słonecznych dni, aby system podgrzewania murawy mógł działać jak najdłużej. W pracy zostały umieszczone wyniki pomiarów z dwóch kompletów czujników. Jeden komplet był zamontowany w boisku, drugi był zamontowany 1 metr poza jego obrębem. Na ich podstawie zostały odczytane temperatury na poszczególnych głębokościach oraz została przeprowadzona analiza.
\end{abstract}

Słowa kluczowe: czujniki, pomiary, temperatura, poziomy gruntowy wymiennik ciepła

\section{Wstęp}

W ciągu ostatnich kilkunastu lat w Polsce można zauważyć wyraźny wzrost zainteresowania pompami ciepła. Pompy te mogą stanowić część systemów grzewczych jednego jak i kilku budynków mieszkalnych, obiektów spor-

${ }^{1}$ mgr inż. Adam Trofimowicz, Politechnika Opolska, Katedra Inżynierii Środowiska, 45-271 Opole, ul. S. Mikołajczyka 5, e-mail: atrofimowicz@gmail.com 
towych a także obiektów użyteczności publicznej [1,2]. Mogą również służyć do ogrzewania płyt boisk sportowych.

Do podgrzewania płyt boisk sportowych stosuje się elektryczne bądź cieczowe systemy. Największą zaletą tych systemów jest wydłużenie czasu wykorzystania boisk w ciągu roku. Elektryczne podgrzewanie murawy boiska realizowane jest za pomocą kabli grzejnych, które są ułożone równolegle do siebie w warstwie gruntu pod powierzchnią murawy. Systemy cieczowe realizowane są za pomocą układu rur ułożonych w ten sam sposób co kable grzejne; w rurach znajduje się ciecz o właściwościach niepodatnych na zamarzanie [13]. Przedmiotem pracy jest zaprezentowanie systemu cieczowego w którym zasilanie instalacji podgrzewania murawy pochodzi z pompy ciepła. Zostaną ponadto przedstawione wybrane wyniki pomiarów dla obiektu sportowego "Orlik" w Praszce, w którym zastosowano pompę ciepła do podgrzewania płyty boiska sportowego.

\section{Rodzaje gruntowych wymienników ciepła}

Do rodzajów gruntowych wymienników ciepła zwanych także dolnymi źródłami pomp ciepła możemy zaliczyć pionowe (Rys. 1.), poziome (Rys. 2.), oraz koszowe gruntowe wymienniki ciepła (Rys. 3.) [3]. Pierwsze z nich montowane są w odwiertach, których głębokość może wynosić ponad 100 m. Do układów możemy zaliczyć wymienniki gruntowe w formie wydłużonej U-rury zamontowane szeregowo lub równolegle z pompą ciepła.
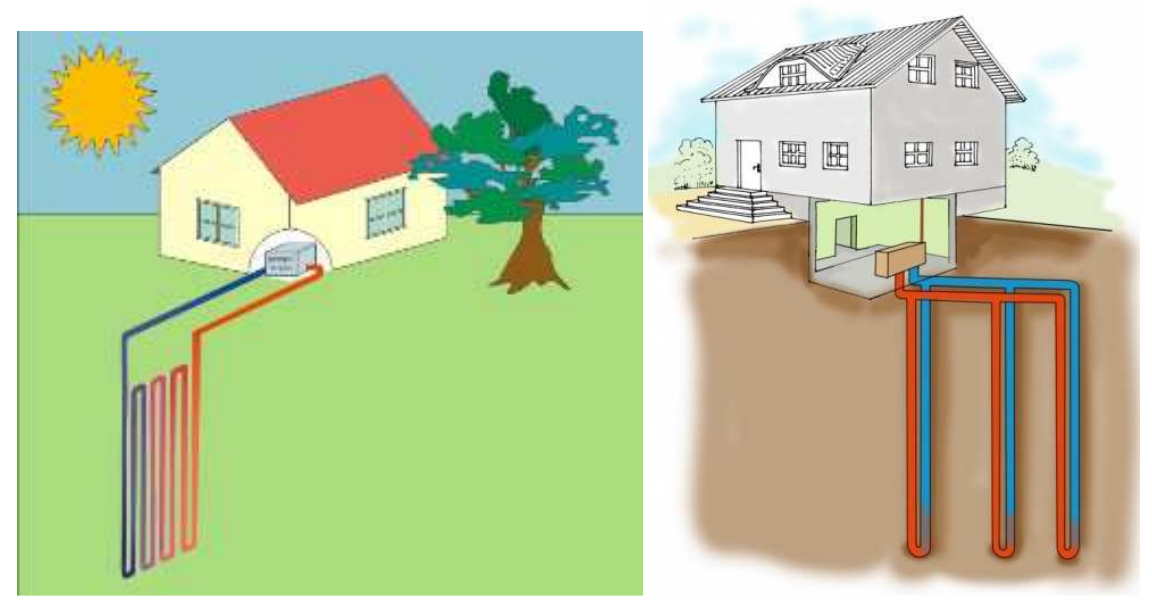

Rys. 1. Pionowy gruntowy wymiennik ciepła. Układ szeregowy (po lewej); układ równoległy (po prawej. www.obud.pl)[4,5]

Fig. 1. Vertical ground heat exchanger. Serial system (on the left); parallel system (on the right. www.obud.pl) $[4,5]$ 
Drugim rodzajem gruntowych wymienników ciepła są wymienniki poziome. Montowane są w glebie na głębokości ok. 1-2 m. Tak jak i wymienniki pionowe, mogą być połączone w układ szeregowy lub równoległy [6].

Ostatnim rodzajem gruntowych wymienników ciepła są wymienniki koszowe zwane także klatkami energetycznymi. Ten typ gruntowych wymienników jest rozwiązaniem dla działek, na których warunki nie pozwalają na montaż tradycyjnych wymienników poziomych [9].

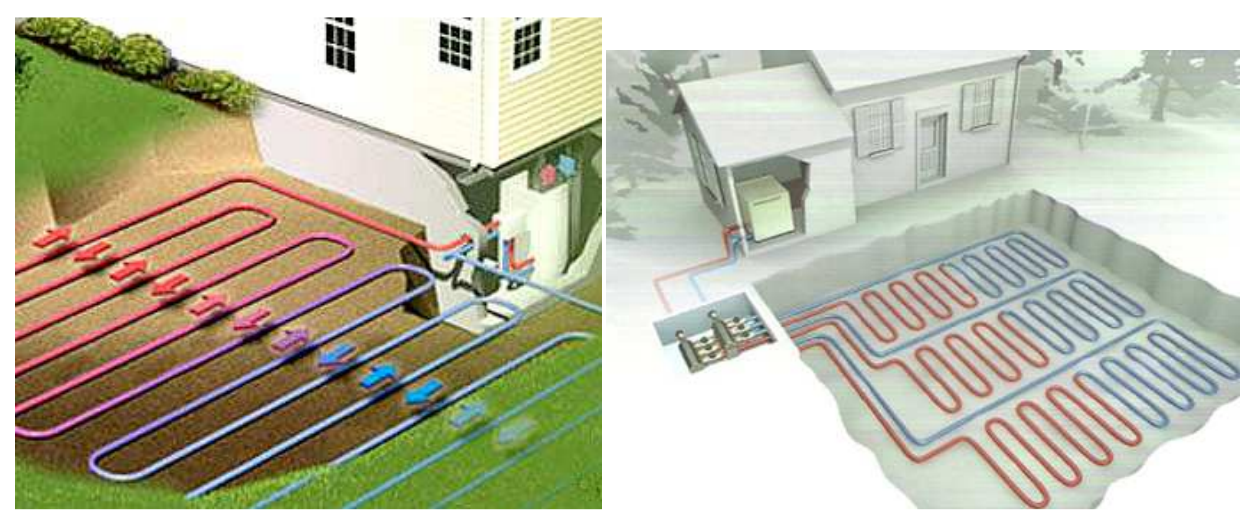

Rys. 2. Poziomy gruntowy wymiennik ciepła. Układ szeregowy (po lewej); układ równoległy (po prawej) $[7,8]$

Fig. 2. Horizontal ground heat exchanger. Serial system (in left); parallel system (in right) $[7,8]$

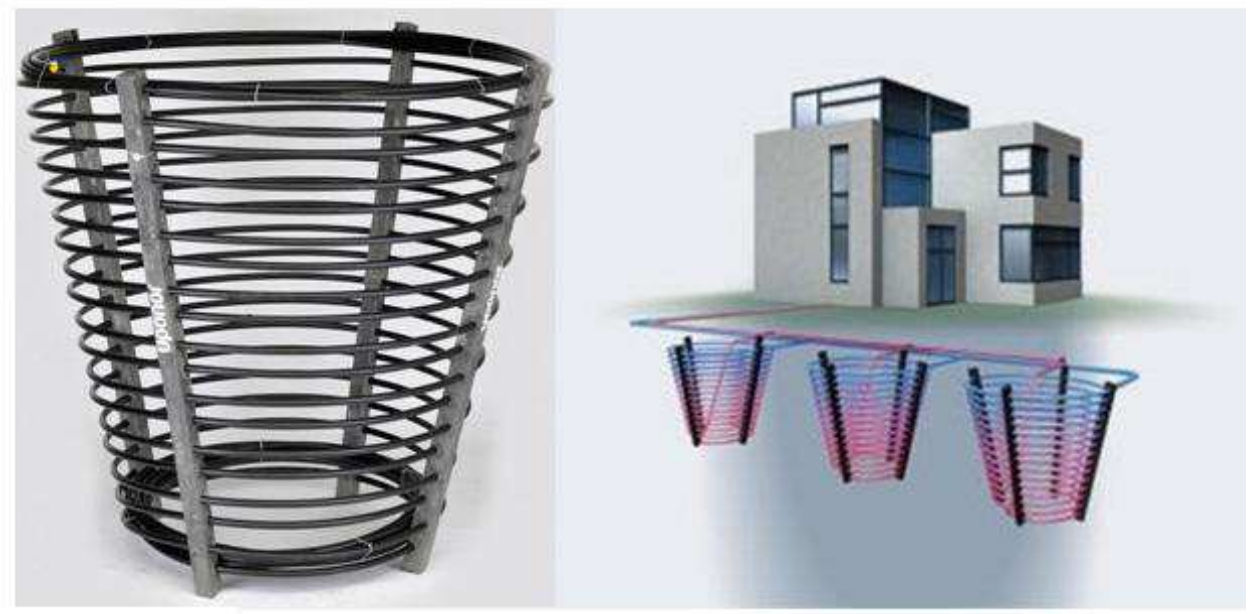

Rys. 3. Klatka energetyczna - gruntowy wymiennik ciepła. Zdjęcie oraz rysunek firmy Uponor [9]

Fig. 3. Energy cage - ground heat exchanger. Photo and drawing: Uponor company [9] 


\section{Kompleks sportowy w Praszce}

Kompleks sportowy w Praszce, w województwie opolskim składa się z boiska piłkarskiego o wymiarach $30 \mathrm{~m}$ x $62 \mathrm{~m} \mathrm{z}$ polem do gry $26 \mathrm{~m}$ x $56 \mathrm{~m}$; boiska wielofunkcyjnego do koszykówki i piłki siatkowej o wymiarach $19,1 \mathrm{~m} \mathrm{x}$ $32,1 \mathrm{~m} \mathrm{z}$ polem do gry o wymiarach $15,1 \mathrm{~m} \mathrm{x} 28,1 \mathrm{~m}$ oraz budynku sanitarno szatniowy o powierzchni użytkowej $63,29 \mathrm{~m}^{2}[10,11]$. Kompleks mieści się w Praszce przy Publicznym Gimnazjum. Boisko do gry w piłkę nożną zostało wyposażone w system podgrzewania murawy oraz system akumulacji ciepła.

\subsection{Elementy systemu}

Głównymi elementami systemu podgrzewania murawy są: pompa ciepła, górne oraz dolne źródło, dwie pompy obiegowe, krata montażowa oraz zbiornik zrzutowy.

Pompa ciepła o nazwie MEZO B oraz mocy grzewczej $65 \mathrm{~kW}$ została umieszczona w tzw. „kotłowni” znajdującej się w budynku tuż przy boisku. W tym samym pomieszczeniu znalazły się zarówno pompy obiegowe służące do wymuszenia ruchu w górnych oraz dolnych źródłach jak i zbiornik zrzutowy, w którym roztwór wody z glikolem (nazywany solanką) może być zmagazynowany $\mathrm{w}$ razie awarii któregokolwiek z elementów systemu. Górne oraz dolne źródła są to układy rur polietylenowych tworzące dwa poziome gruntowe wymienniki ciepła. Jeden znajduje się na głębokości $\sim 0,9 \mathrm{~m}$ i ma za zadanie odbierać ciepło. Drugi gruntowy wymiennik ciepła znajduje się na głębokości $0,1 \mathrm{~m}$ i ma za zadnie oddawać ciepło (podgrzewać murawę w zimie). Rury górnego źródła ułożone są na kracie montażowej o nazwie Technogrid, która ma zadanie utrzymania odstępów $0,15 \mathrm{~m}$ między poszczególnymi rurami.

Do głównych elementów systemu akumulacji ciepła należą: kolektory słoneczne, płaszczowo-rurowy wymiennik ciepła, dwie pompy obiegowe, sterownik pomp obiegowych oraz układ rur służący do akumulacji ciepła w gruncie.

Na rysunku 4 pokazano przekrój boiska ze schematem rozmieszczenia rur.

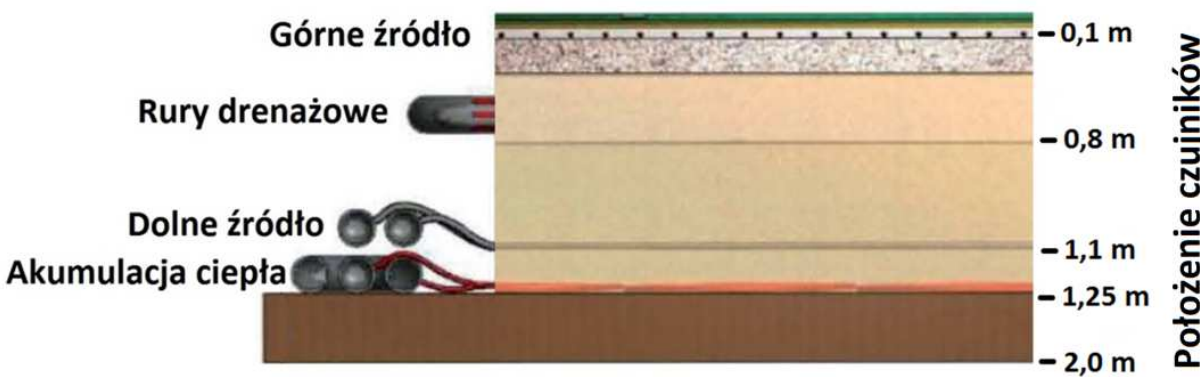

Rys. 4. Schemat rozmieszczenia rur oraz czujników w boisku [10]

Fig. 4. Scheme of pipes location and sensors in the outdoor sports ground [10] 
Analiza pracy systemu podgrzewania płyty boiska sportowego z wykorzystaniem... 549

Dwanaście płaskich kolektorów słonecznych o wymiarach $2,164 \times 1,014 \times 0,08 \mathrm{~m}$, zostało zamontowanych na budynku sanitarnoszatniowym. Cała instalacja akumulacji ciepła została wypełniona roztworem wody z glikolem. Kolejnym elementem systemu jest płaszczowo-rurowy wymiennik ciepła. Ma on za zadanie przekazanie ciepła z roztworu glikolu płynącego w płaskich kolektorach słonecznych do roztworu glikolu, znajdującego się w rurach akumulacji ciepła znajdujących się pod powierzchnią gruntu na głębokości 1m. Do wymuszenia ruchu roztworu wody z glikolem użyto dwóch pomp. Jedna służyła do wymuszenia ruchu w obiegu instalacji solarnej. Druga do wymuszenia ruchu w instalacji akumulacji ciepła. Sterownik pomp obiegowych służy do włączania oraz wyłączania pomp na podstawie czujników temperatury zainstalowanych na wlocie oraz wylocie z kolektorów słonecznych [10].

Celem systemu akumulacji ciepła jest zmagazynowanie jak największej ilości ciepła w gruncie aby system podgrzewania murawy mógł jak najdłużej działać.

\section{Wyniki pomiarów}

Celem pomiarów było sprawdzenie poprawności działania systemu podgrzewania murawy. $\mathrm{W}$ tym celu na etapie budowy boiska, w gruncie umieszczono czujniki firmy Tewa Electronics Group o oznaczeniu PT1000. Rozmieszczono je między innymi w punktach A oraz B przedstawionych na rysunku poniżej (Rys. 5.). Pomiary przeprowadzono z wykorzystaniem miernika uniwersalnego firmy UNI-T o oznaczeniu UT $71 \mathrm{E}$. W tabeli 1 przedstawiono wybrane wyniki pomiarów, wykonanych w dniu 21.01.2014 roku. Był to mroźny dzień $\mathrm{z}$ opadami deszczu ze śniegiem. Temperatura $\mathrm{w}$ trakcie pomiaru o godzinie 17.00 wynosiła $-2,5^{\circ} \mathrm{C}$. Czujniki w boisku zostały zamontowane z chwilą budowy boiska i znajdują się na linii środkowej boiska, w odległości $10 \mathrm{~m}$ od jego krawędzi. Rury służące do podgrzewania murawy, pobierania ciepła z gruntu, oraz akumulacji ciepła zostały podłączone w układ Tichelmanna. Jest to układ który zapewnia jednakowe straty ciśnienia, oraz prędkości na wszystkich rurach za pomocą odpowiedniego podłączenia rur. Bez konieczności użycia kryz [12]. Stąd odległość od krawędzi boiska nie miała większego znaczenia. Lecz aby wyeliminować wpływ temperatur z gruntu rodzimego zdecydowano się o umieszczeniu czujników w odległości $10 \mathrm{~m}$ gdzie temperatura systemu jest ustabilizowana. Czujniki poza obrębem boiska znajdują się 1 metr od krawędzi boiska i znajdują się w gruncie rodzimym . 

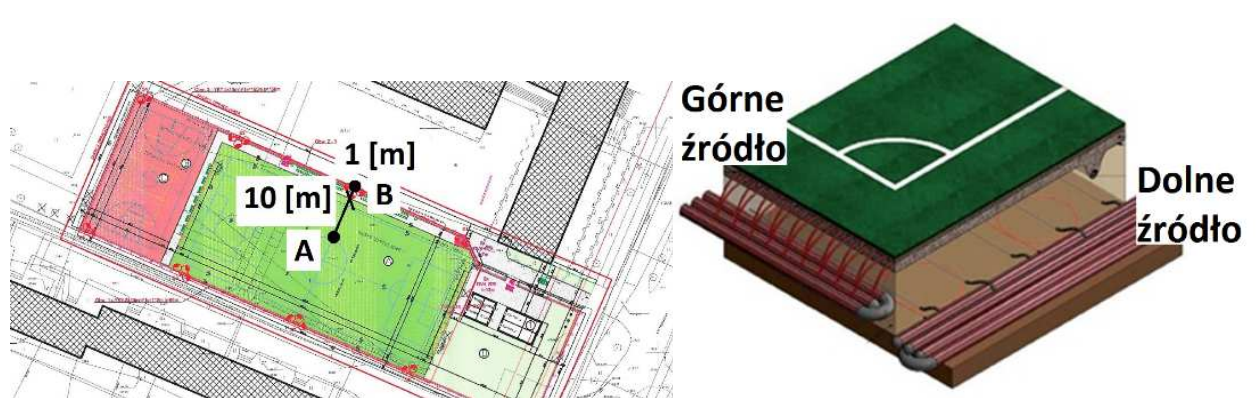

Rys. 5. Schemat boiska z lokalizacją czujników (po lewej); Schemat rur, górnego oraz dolnego źródła (po prawej) [10]

Fig. 5. Scheme of the outdoor sports ground with the sensors location (on the left); Scheme of tubes, upper and lower source (on the right) [10]

Tabela 1. Wybrane wyniki pomiarów z dnia 21-01-2014

Table 1. Selected results of measurements on 21-01-2014

\begin{tabular}{|c|c|c|}
\hline $\begin{array}{c}\text { Położenie czujników od poziomu } \\
\text { gruntu }[\mathrm{m}]\end{array}$ & $\begin{array}{c}\text { Temperatura z czujni- } \\
\text { ków umieszczonych w } \\
\text { boisku } \\
{\left[{ }^{\circ} \mathrm{C}\right]}\end{array}$ & $\begin{array}{c}\text { Temperatura z czujni- } \\
\text { ków umieszczonych } \\
\text { poza obrębem boiska } \\
{\left[{ }^{\circ} \mathrm{C}\right]}\end{array}$ \\
\hline 0,1 & 0,5 & 0,0 \\
\hline 0,8 & 3,5 & 5,0 \\
\hline 1,1 & 3,0 & 3,5 \\
\hline 1,25 & 3,0 & 4,0 \\
\hline 2 & 5,0 & 5,5 \\
\hline
\end{tabular}

$\mathrm{Z}$ tabeli 1. wynika, że podczas podgrzewania murawy czujnik znajdujący się w boisku na głębokości $1,1 \mathrm{~m}$ wskazuje temperaturę niższą niż ten, który znajduje się w boisku na głębokości $0,8 \mathrm{~m}$, co świadczy o pobieraniu ciepła $\mathrm{z}$ gruntu. $\mathrm{Z}$ czujników umieszczonych poza obręb boiska wynika również, że pomimo oddalenia ich o metr poza krawędź boiska, dolne źródło nadal ma wpływ na grunt wokół tych czujników. Wyraźnie widać to po wynikach pomiarów, otrzymanych z czujnika, znajdującego się poza obrębem boiska na głębokości $1,1 \mathrm{~m}$, w którym temperatura w porównaniu do czujników, umieszczonych poza obrębem boiska na głębokości $0,8 \mathrm{~m}$ i 1,25 m jest niższa. Porównując wyniki zawarte w tabeli można zauważyć, że temperatury odczytane z czujników umieszczonych poza obrębem boiska są wyższe. Poza jedną, znajdującą się, na głębokości $0,1 \mathrm{~m}$. Może świadczyć to o częściowym wyczerpaniu dolnego źródła ciepła, które znajduje się w boisku; wyższa wartość temperatury w czujniku umieszczonym w boisku na głębokości 0,1 m świadczy o oddawaniu ciepła przez pompę ciepła. 
Analiza pracy systemu podgrzewania płyty boiska sportowego z wykorzystaniem... 551

\section{Podsumowanie}

Omówiony system podgrzewania murawy w zimie za pomocą pompy ciepła odbiera pokłady energii cieplnej dolnego źródła i przekazuje ją do górnego źródła, które podgrzewa murawę boiska. Podczas dużych, długotrwałych mrozów system nie działa poprawnie. Sterownik pompy ciepła, ze względu na zbyt niskie temperatury solanki na wypływie z pompy wyłącza ją, co dzieje się przy temperaturze $-10{ }^{\circ} \mathrm{C}$. Poza tym w „kotłowni”, w miejscach łączeń zaworów, gdzie nie ma założonej izolacji, na rurze podłączonej z jednej strony do pompy ciepła a z drugiej do dolnego źródła, powstaje warstwa lodu (z wierzchu wyglądająca jak szron). Wykroplenie się wilgoci z powietrza na ściankach zewnętrznych rury zachodzi ponieważ pomiędzy temperaturą wilgotnego powietrza w pomieszczeniu a temperaturą ścianki rury jest duża różnica temperatur (w pomieszczeniu temperatura około $22{ }^{\circ} \mathrm{C}$; w rurze temperatura solanki wypływającej z pompy ciepła dochodzi do $-10{ }^{\circ} \mathrm{C}$ ). Warstwa lodu nie pozwala na regulację zaworów, dlatego osoba obsługująca instalację stwierdzając, że warstwa lodu jest zbyt gruba wyłącza ją do momentu stopienia się lodu. Podczas tych przestojów zanika możliwość podgrzewania murawy, co za tym idzie w zimie podczas opadów śniegu system nie wypełnia swojej podstawowej roli.

Rekomendacją na tym obiekcie mogłoby być zamontowanie większej ilości kolektorów słonecznych co zwiększyłoby uzysk ciepła słonecznego.

\section{Literatura}

[1] Zalewski W.: Pompy ciepła sprężarkowe, sorpcyjne i termoelektryczne. IPPU Masta, Gdańsk 2001.

[2] Zawadzki M.: Kolektory słoneczne, pompy ciepła - na tak. Polska Ekologia 2003.

[3] http://issuu.com/instalreporter.pl/docs/instalreporter_2013_10/40, strona 63 [dostęp: 5 kwiecień 2014 r.].

[4] http://www.biomasa.org/index.php?d=artykul\&kat=165\&art=166 [dostęp: 5 kwiecień 2014 r.].

[5] http://www.obud.pl/wiadomosci,art,8727,,dolne_rodlo_pompy_ciepla_musi_miec_ odpowiednia_wielkosc_cykl_uwaga_na_bledy_czesc_pierwsza [dostęp: 5 kwiecień 2014 r.].

[6] Rubik M.: Pompy ciepła. Poradnik. Ośrodek Informacji: Technika instalacyjna w budownictwie, Warszawa 2006.

[7] http://portalenergia.pl/wiadomosci/technologie/dolne-zrodla-pomp-ciepla,127 [dostęp: 3 maj 2014 r.].

[8] http://www.engeco.pl/zestawy-dolnego-zrodla/ [dostęp: 3 maj 2014 r.].

[9] Serafin P.: Klatki energetyczne - nowy rodzaj kolektorów gruntowych. InstalReporter sierpień 2013 (08) str 50-51, http://instalreporter.pl/wp-content/uploads /2013/08/IR_2013_08_Klatki_energetyczne.pdf [dostęp: 3 maj 2014 r.].

[10] http://www.rudniki.internetdsl.pl/orlikpraszka.zip [dostęp: 5 styczeń 2014 r.]. 
[11] http://orlik2012.pl/dev.php/dla-inwestorow/zalozenia [dostęp: 3 maj 2014 r.].

[12] http://www.instalator.pl/ABC/2007/zrzut/pdf_09_2007/Page\%2026.pdf [dostęp: 3 maj 2014 r.].

[13] http://wis.pol.lublin.pl/kongres3/tom3/19.pdf [dostęp: 3 maj 2014 r.].

\section{HEATING SPORTS GROUND USING HEAT PUMP}

\section{S u m m a r y}

This article is about the system which heats the outdoor sports ground located in Praszka nearby a centrally located school. It describes main elements of this system and presents types of the ground heat exchangers. Furthermore it includes the results of measurements from two sets of sensors. Both results is measured in one cold day but in two different places. One set was placed within the sports ground, the other one was placed 1 meter far outside. On the basis their temperatures were read at various depths and the analysis was conducted. System of heating the ground in the winter by means of a heat pomp receives the heating energy from the lower source and transfers it to the upper source which warms up the grounds surface. During the long cold periods the system is not working very well. Due to too low temperature of the brine at the exit of the pomp, heat pomp driver switches it off. It happens at the temperature of $-10{ }^{\circ} \mathrm{C}$. Additionally the ice settling at the tubes makes regulation of valves impossible and the pomp needs to be switched off till the ice melts. During those periods the possibility of heating the ground disappears and as a consequence the system doesn't fulfill its crucial role during the snowfalls in the wintertime.

Keywords: sensors, measurement, temperature, horizontal ground heat exchanger

Przesłano do redakcji: 10.01.2015 r.

Przyjęto do druku: 22.06.2015 r.

DOI:10.7862/rb.2015.83 